\title{
Native target chemistry during reactive dc magnetron sputtering studied by ex-situ x-ray photoelectron spectroscopy
}

Grzegorz Greczynski, S. Mraz, J . M. Schneider and Lars Hultman

The self-archived version of this journal article is available at Linköping University Institutional Repository (DiVA):

http:// urn.kb.se/ resolve?urn=urn:nbn:se:liu:diva-139818

N.B.: When citing this work, cite the original publication.

Greczynski, G., Mraz, S., Schneider, J . M., Hultman, L., (2017), Native target chemistry during reactive dc magnetron sputtering studied by ex-situ x-ray photoelectron spectroscopy, Applied Physics Letters, 111(2), . https:/ / doi.org/ 10.1063/ 1.4993787

Original publication available at:

https:/ / doi.org/ 10.1063/ 1.4993787

Copyright: AIP Publishing

http:// www.aip.org/ 


\title{
Native target chemistry during reactive dc magnetron sputtering studied by $e x$-situ $x$-ray photoelectron spectroscopy
}

\author{
G. Greczynski, ${ }^{1,2}$ S. Mráz, ${ }^{2}$ J.M. Schneider, ${ }^{2}$ and L. Hultman ${ }^{1}$ \\ ${ }^{1}$ Thin Film Physics Division, Department of Physics (IFM), Linköping University, \\ SE-581 83 Linköping, Sweden \\ ${ }^{2}$ Materials Chemistry, RWTH Aachen University, Kopernikusstr. 10, D-52074 Aachen, \\ Germany
}

\begin{abstract}
We report $x$-ray photoelectron spectroscopy (XPS) analysis of native Ti target surface chemistry during magnetron sputtering in $\mathrm{Ar} / \mathrm{N}_{2}$ atmosphere. To avoid air exposure, the target is capped immediately after sputtering with a few-nm-thick Al overlayers, hence, information about the chemical state of target elements as a function of $\mathrm{N}_{2}$ partial pressure $p_{N 2}$ is preserved. Contrary to previous reports, which assume stoichiometric TiN formation, we present direct evidence, based on core-level XPS spectra and TRIDYN simulations, that target surface is covered by $\operatorname{TiN}_{x}$ with $x$ varying in a wide range, from 0.27 to 1.18 , depending on $p_{N 2}$. This has far-reaching consequences both for modelling of the reactive sputtering process as well as for everyday thin film growth where detailed knowledge of the target state is crucial.
\end{abstract}

Keywords: TiN, XPS, magnetron sputtering, target poisoning, nitrogen implantation 
Reactive magnetron sputtering is an essential tool for producing advanced functional coatings with wide range of applications from wear-resistant layers on cutting tools ${ }^{1,2}$ engine components, ${ }^{3,4}$ to diffusion barriers in electronic devices. ${ }^{5,6}$ The presence of a reactive gas, however, leads not only to the desired compound formation at the substrate, but also to gas chemisorption at the target and subsequent growth of compound layer, by so-called target poisoning. The latter results in severe reduction in the sputtering rate, change in the chemical composition of the sputtered flux as well as the energy distribution thereof, ${ }^{7,8}$ ion implantation effects, ${ }^{9}$ and process hysteresis. ${ }^{10,11}$

Nitridation of metal target surface during magnetron sputtering in $\mathrm{Ar} / \mathrm{N}_{2}$ gas mixtures has been reported experimentally in early 80 's, ${ }^{12}$ with few later attempts to measure compound film thickness. Güttler et al. performed real-time in situ analysis of Ti target sputtered in $\mathrm{Ar} / \mathrm{N}_{2}$ gas mixture using nuclear reaction methods and calculated TiN compound layer thickness from measured $\mathrm{N}$ areal density to be $2.5 \mathrm{~nm}$ at higher $\mathrm{N}_{2}$ flows. ${ }^{13}$ In situ ellipsometry studies of Si target sputtered in $\mathrm{Ar} / \mathrm{N}_{2}$ and $\mathrm{Ar} / \mathrm{O}_{2}$ mixtures revealed that thickness of formed nitride and oxide may reach respectively 4 and $7 \mathrm{~nm}$, if $100 \%$ reactive gas is used. ${ }^{14}$ Two orders of magnitude larger compound layer thicknesses (up to $500 \mathrm{~nm}$ ), were measured by nuclear reaction analysis (NRA) and glow discharge optical emission spectroscopy for Ti target operated in an oxygen-containing atmosphere by high power impulse magnetron sputtering. ${ }^{15}$ While NRA is ideally suited to gain depth resolved composition information, no information about the chemical state can be obtained which hinders correct assessment of target surface conditions. In all cases listed above, the formation of stoichiometric compounds was assumed for the layer thickness calculation. However, given the fact that the target surface is continuously exposed to a flux of reactive gas ions which are accelerated across the cathode fall of several hundred $\mathrm{eV}$, a certain nitrogen or oxygen concentration gradient in the target surface region cannot be a priori excluded. One may, hence, question the very notion of 
stoichiometric compound formation, independent of reactive gas partial pressure.

X-ray photoelectron spectroscopy (XPS) is commonly used to determine surface chemistry of magnetron sputtered thin films and its probing depth, typically 5-10 nm, makes it particularly suited for analyses of layers formed on sputtering targets. Nevertheless, such XPS analyses are rare $^{16,17}$ and limited to extracting the reactive element content without reporting the actual spectra. A majority of the existing XPS literature on nitrided targets is dedicated to in-situ analyses of ion-implanted samples, ${ }^{18,19,20,21}$ subjected to an ion beam of well-defined energy (typically a few $\mathrm{keV}$ ). The latter conditions do not directly reflect the entire spectrum of processes taking place during magnetron sputtering, where various types of ion species are present with energies and fluxes that are only approximately known.

One reason for the lack of XPS studies of nitride target surfaces is oxidation ${ }^{22}$ upon airexposure during transport to the spectrometer, as vast majority of magnetron sputtering systems lack in situ XPS capabilities. This undesired surface modification impedes reliable XPS analyses of target chemistry. $\mathrm{Ar}^{+}$-ion etch extensively used to clean as-received surfaces results in a range of destructive effects like cascade mixing, recoil implantation, surface roughening, preferential sputtering, and forward implantation of surface species. ${ }^{23}$ To circumvent these problems, we recently demonstrated that a few nm thick metal capping layers deposited immediately after film growth prevent oxidation of polycrystalline TM nitride surfaces during transport in air from magnetron sputtering system into the XPS instrument. ${ }^{24}$ In this way, high quality core level spectra directly comparable to those acquired from films grown and analyzed in situ in a ultrahigh-vacuum (UHV) XPS system can be acquired. ${ }^{25}$

Here, we report high-energy resolution core-level photoelectron spectra obtained ex situ from native Ti targets after magnetron sputtering in $\mathrm{Ar} / \mathrm{N}_{2}$ atmospheres. Targets are in situ capped, immediately after the film growth, with a few nm thick metal overlayers prior to airexposure to prevent oxidation during transfer from the growth chamber into the XPS 
instrument. Experiments are performed as a function of $\mathrm{N}_{2}$ partial pressure $p_{N 2}$. In contrast to previous reports, formation of stoichiometric TiN is not a priori assumed. Rather than that, $\mathrm{Ti}$ 2p and $\mathrm{N}$ 1s spectra together with the TRIDYN-simulated $\mathrm{N}$ implantation profiles are used to reveal the $\operatorname{TiN}_{x}$ stoichiometry as a function of $p_{N 2}$. Ti and $\operatorname{TiN}_{x}$ contributions, clearly resolved in Ti $2 p$ spectra recorded at higher $p_{N 2}$, allow for precise estimates of the $\mathrm{TiN}_{x}$ thickness.

A multi-cathode CC800/9 CemeCon AG magnetron sputtering system is used for these experiments. ${ }^{26}$ A rectangular $8.8 \times 50 \mathrm{~cm}^{2}$ Ti target is operated in dc magnetron sputtering (DCMS) using $\mathrm{Ar} / \mathrm{N}_{2}$ gas mixtures. The $\mathrm{O}_{2}$ content in the target is $0.18 \mathrm{wt} \%$, which is on the detection limit of XPS, and certainly well below concentrations necessary to cause significant changes in the Ti 2p and $\mathrm{N}$ 1s spectra of TiN. A $2 \times 4 \mathrm{~cm}^{2}$ section of the target, positioned in the middle and across the race track, is made detachable to allow for transfer to XPS system. The background pressure prior to sputtering is $0.2 \mathrm{mPa}\left(1.5 \times 10^{-6}\right.$ Torr $)$. The total pressure is kept constant at $0.4 \mathrm{~Pa}$ (3 mTorr), while the $\mathrm{N}_{2}$ partial pressure $p_{N 2}$ is varied from 0 to $200 \mathrm{mPa}$. The average target power is $2 \mathrm{~kW}$, while target voltage changes from $-331 \mathrm{~V}$ with $p_{N 2}=0 \mathrm{mPa}$ to $-353 \mathrm{~V}$ for the highest $\mathrm{N}_{2}$ content in the gas mixture. Prior to each experiment, the target is conditioned for $5 \mathrm{~min}$. in pure Ar behind closed shutters to reset the target history. For each gas mixture studied, target is operated for $10 \mathrm{~min}$. to assure steady-state conditions.

In order to prevent oxidation, Al-caps are deposited following the growth. First, the $\mathrm{Al}$ target, intended for cap layer deposition, is sputter-cleaned in Ar for $120 \mathrm{~s}$ at $2 \mathrm{~kW}$ behind closed shutters. We do not expect any chemical reactions on the target side during this time, as previous studies indicate that the post-deposition exposure of freshly-grown films to residual gases, including oxygen and water vapor, does not affect surface chemistry. ${ }^{27}$ After that, power is reduced to $0.4 \mathrm{~kW}$ and capping overlayer is deposited on the Ti target with the thickness of $50 \pm 5 \AA$, as estimated from the attenuation of core level signals using electron inelastic mean 
free paths reported by Tanuma et al. ${ }^{28}$ Subsequently, Ti target fragment is transferred to the load-lock chamber of the UHV XPS system. The total air exposure time is shorter than $2 \mathrm{~min}$.

Core-level XPS spectra are obtained in an Axis Ultra DLD instrument from Kratos Analytical (UK) with the base pressure during spectra acquisition lower than $1.5 \times 10^{-7} \mathrm{~Pa}$ $\left(1.1 \times 10^{-9}\right.$ Torr $)$ operating monochromatic $\mathrm{Al} \mathrm{K} \alpha$ source $(\mathrm{h} v=1486.6 \mathrm{eV})$. All spectra are collected at normal emission angle from the $0.3 \times 0.7 \mathrm{~mm}^{2}$ area centered in the middle of the target race track. Spectra deconvolution and quantification are performed using CasaXPS software package. ${ }^{29} \mathrm{BE}$ scale is calibrated against the Fermi level cut-off, ${ }^{30}$ using the procedure described in detail elsewhere, what helps avoid BE referencing problems resulting from the fact that $\mathrm{C} 1 \mathrm{~s} \mathrm{BE}$ depends on the type of surface oxides formed during venting procedure, ${ }^{27}$ and removes ambiguities related to the use of $\mathrm{C} 1 \mathrm{~s}$ as the BE reference. ${ }^{31}$

Normalized Ti 2p spectra recorded from Al-capped Ti target sputtered in $\mathrm{Ar} / \mathrm{N}_{2}$ mixture with the $\mathrm{N}_{2}$ partial pressure varying from 0 to $200 \mathrm{mPa}$ are shown in Fig. 1. For clarity, we focus our discussion to the stronger $2 \mathrm{p}_{3 / 2}$ component of the spin-split doublet.

In the case of sputtering in pure $\mathrm{Ar}, \mathrm{Ti} 2 \mathrm{p}$ signal acquired from the target is characteristic of metallic $\mathrm{Ti}$, with the $\mathrm{Ti} 2 \mathrm{p}_{3 / 2}$ peak at $454.0 \mathrm{eV}$ and the overall shape very similar to the reference Ti 2p spectra from metallic Ti films shown in Fig. 2(a). With increasing $\mathrm{N}_{2}$ component in the sputtering gas to $9 \mathrm{mPa}$ the Ti 2p/2 peak moves to $454.2 \mathrm{eV}$ and broadens on the higher BE side indicative of a new contribution. The latter component, assign to $\operatorname{TiN}_{x}$, becomes more pronounced after sputtering at $p_{N 2}=27 \mathrm{mPa}$. In this case, the $\mathrm{BE}$ of the $\mathrm{TiN}_{x}$ feature, $454.60 \mathrm{eV}$, is between that of a metal and a stoichiometric nitride $(455.0 \mathrm{eV})$. For $p_{N 2}$ $=45 \mathrm{mPa}$, the $\operatorname{TiN}_{x}$ peak shifts to $454.9 \mathrm{eV}$ and dominates the signal. Finally with $p_{N 2} \geq 92$ $\mathrm{mPa}$, Ti 2p3/2 moves to $455.0 \mathrm{eV}$, characteristic of a stoichiometric TiN. This spectral evolution from metallic to nitrided layer, associated with a gradual shift of $\mathrm{Ti} 2 \mathrm{p}_{3 / 2} \mathrm{BE}$, is consistent with earlier reports. ${ }^{32}$ The appearance of the Ti $2 \mathrm{p}$ spectra at higher $p_{N 2}$ values, with two distinct 
contributions from $\mathrm{Ti}$ and $\mathrm{TiN}_{x}$, indicates a layer-over-layer structure, which is confirmed by the angle-resolved Ti 2p spectra (not shown) and TRIDYN modelling discussed below. The corresponding set of $\mathrm{N}$ 1s spectra (not shown), indicated an increasing signal intensity with increasing $p_{N 2}$, in agreement with the evolution of Ti 2p spectra discussed above. Spectra consisted of a main peak centered at $397.1-397.4 \mathrm{eV}$, corresponding to $\mathrm{TiN}_{x},{ }^{25}$ and an asymmetric tail on the high $\mathrm{BE}$ side, more apparent in the spectrum obtained from targets sputtered with $p_{N 2} \geq 0.27 \mathrm{mPa}$. Indeed, previously reported high-resolution TiN core level spectra of thin films contain satellite features also in the $\mathrm{N}$ 1s signal. ${ }^{33}$ In the present case, however, the satellite contribution was smeared out, because of ion-induced damage of the target surface. ${ }^{24}$ In the case of the target sputtered at $p_{N 2}=200 \mathrm{mPa}$, the increase in main peak full-width-at-half-maximum (FWHM) together with high-intensity tail on the high BE side were likely the result of $\mathrm{N}$ overstoichiometry with nitrogen atoms occupying interstitial sites.

To interpret the complex Ti 2p spectra of Fig. 1, we construct a peak model using the input from XPS measurements performed on reference Ti and TiN films, shown in Figs. 2(a) and 2(b), respectively. In all cases, a Shirley background ${ }^{34}$ is used. The apparent asymmetry observed for main peaks in $\mathrm{Ti}$ and TiN spectra is represented by Voigt functions with tail modifiers. ${ }^{35}$ The TiN model includes also satellite peaks on the high BE side of the primary signals (TiN-sat in Fig. 2(b)) represented with Voigt functions. While the origin of these features is under discussion ${ }^{36,37,38,39}$ appealing evidence points towards shake up effects due to intraband transitions between filled and partially filled valence electron energy levels near the Fermi energy, ${ }^{40}$ and a decrease in the screening ability of the conduction electrons leading to “well-screened” and "poorly-screened” XPS peaks. ${ }^{32}$

In order to extract physically meaningful information, the line shapes for pairs of $\mathrm{Ti}$, TiN, and TiN-sat peaks, $2 \mathrm{p}_{3 / 2}-2 \mathrm{p}_{1 / 2}$ energy splitting and the $2 \mathrm{p}_{3 / 2} / 2 \mathrm{p}_{1 / 2}$ area ratios are first obtained by fitting the reference Ti and TiN spectra, and then used as input to construct more 
complex peak models like the one shown in Fig. 2(c) for a Ti target sputtered with $p_{N 2}=92$ mPa. Further to the above constraints, also the BE difference between TiN and TiN-sat peaks are fixed at a value determined from the TiN reference spectrum. The fitting parameters include full-width-at-half-maximum, 2p $3 / 2$ peak positions and intensities.

With this restrictive modelling, we obtain satisfactory fits to Ti 2p spectra shown in Fig. 1 with $p_{N 2} \geq 92 \mathrm{mPa}$, i.e., in cases where two distinct Ti chemical states are present. This, together with angle-resolved XPS data that show a decrease of the metallic peak at higher tilt angles, indicates a structure consisting of a compound layer on top of a metallic Ti. The N/Ti ratio $(x)$ in the $\operatorname{TiN}_{x}$ overlayer extracted from the model is 0.98 and 1.18 for $p_{N 2}$ equal to 92 , and $200 \mathrm{mPa}$, respectively. The overstoichiometry in the case of the highest $\mathrm{N}_{2}$ partial pressure is consistent with the evolution of the corresponding $\mathrm{N}$ 1s spectra. From the fact that Ti 2p spectra for $p_{N 2} \leq 45 \mathrm{mPa}$ cannot be fitted with $\mathrm{Ti}$ and TiN contributions we infer the formation of substoichiometric nitride at lower $\mathrm{N}_{2}$ partial pressures. In the latter cases the N/Ti ratios extracted from Ti 2p and N 1s peak areas vary from 0.27 with $p_{N 2}=9 \mathrm{mPa}$, to 0.60 and 0.69 with $p_{N 2}$ increased to 27 and $45 \mathrm{mPa}$, respectively.

The evolution of XPS signals with varying gas composition can be compared to dynamic Monte Carlo collisional computer simulations using TRIDYN code ${ }^{41,42}$ of the stationary nitrogen depth profiles, as resulting primarily from the implantation of energetic nitrogen ions, recoil implantation, atomic mixing, and resputtering. During DCMS with $\mathrm{Ar} / \mathrm{N}_{2}$ gas mixtures optimized to obtain stoichiometric films, the majority ion species incident at the growing film are $\mathrm{Ar}^{+}, \mathrm{N}_{2}{ }^{+}$, and $\mathrm{N}^{+}$, with the $\mathrm{N}_{2}{ }^{+} / \mathrm{N}^{+}$ratio increasing with increasing $p_{N 2 .}{ }^{43}$ Our previously reported in situ ion mass spectrometry measurements of Ti-DCMS plasma with $p_{N 2}$ $=80 \mathrm{mPa}$ showed that $\mathrm{N}_{2}{ }^{+}$population is $\sim 50$ times higher than $\mathrm{N}^{+},{ }^{44}$ thus, in TRIDYN simulations we neglect the latter species. The $\mathrm{N}_{2}{ }^{+}$ion content in the plasma relative to $\mathrm{Ar}^{+}$can be approximated by the $\mathrm{N}_{2} / \mathrm{Ar}$ partial pressure ratio, since under DCMS conditions both gases 
have similar electron impact ionization cross sections. ${ }^{45}$ The cathode sheaths are collision-less, thus, if we take into account the fact that the plasma potential is not higher than a few volts, the incident ion energy can be approximated by the target voltage. ${ }^{46}$ Therefore, in simulations, we use $340 \mathrm{eV} \mathrm{Ar}$, while each $\mathrm{N}_{2}{ }^{+}$ion upon impact at the growing film surface gives rise to two $\mathrm{N}^{+}$species each arriving with $170 \mathrm{eV}$.

Fig. 3 shows the simulated N/Ti depth profiles $x(d)$ for a range of $\mathrm{N}^{+} / \mathrm{Ar}^{+}$flux ratios that correspond to $p_{N 2}$ values used in experiments. Results are shown for $2 \times 10^{5}$ pseudoparticles representing the total fluence of $5 \times 10^{17}$ ions $/ \mathrm{cm}^{2}$, corresponding to the steady-state conditions. Comparison of $x(d)$ profiles to XPS results leads to interesting revelations. With $p_{N 2}=9 \mathrm{mPa}$, simulations indicate $x=0.2$ and gradually decaying with increasing depth, consistent with the XPS results that reveal Ti 2p spectrum only slightly different from that of a metallic Ti and the $\mathrm{N}$ 1s peak of relatively low intensity. Higher $p_{N 2}$ value of $27 \mathrm{mPa}$ results in a qualitative change in the TRIDYN-calculated profile, with $x$ between 0.6 and 0.7 within first $20 \AA$, which is also reflected in the corresponding Ti 2p spectrum that exhibits a pronounced shoulder on the higher $\mathrm{BE}$ side of the metallic peak, accompanied by a rapid increase in the $\mathrm{N}$ 1s peak intensity. For the $p_{N 2}=45 \mathrm{mPa}$ case, TRIDYN indicates $x \sim 0.9$ up to $d=26 \AA$ after which a rapid decay takes place. With further increasing $\mathrm{N}_{2}$ partial pressure to 92 and $200 \mathrm{mPa}$, the simulated profile indicates close-to-stoichiometric $\mathrm{TiN}_{x}$ with $x=0.94$ and 0.96 , respectively, which forms a relatively sharp interface to metallic Ti at $32 \pm 2 \AA$. The later number can be compared to the $\mathrm{TiN}_{x}$ thickness $\boldsymbol{d}_{\boldsymbol{T i N}_{\boldsymbol{x}}}$ obtained from the relative peak intensities of metal and nitride components in the fitted Ti 2p XPS spectra according to ${ }^{47,48}$

$$
d_{T i N_{x}}=\lambda_{T i N_{x}} \ln \left(\frac{n_{T i} \lambda_{T i} I_{T i N_{x}}}{n_{T i N_{x}} \lambda_{T i N_{x}} I_{T i}}+1\right)
$$

in which $\lambda$ is the inelastic electron mean free path, $n_{T i}$ and $n_{T i N_{x}}$ are the volume densities of Ti atoms in $\mathrm{Ti}$ and $\mathrm{TiN}_{x}$, and $I_{T i}$ and $I_{T i N_{x}}$ are the Ti 2p peak intensities of $\mathrm{Ti}$ and $\mathrm{TiN}_{x}$ 
components extracted from the peak model. $n_{T i} / n_{T i N_{x}}=1.46 / x$ for hexagonal close-packed Ti and cubic $\operatorname{TiN}_{x}$. We assume $\lambda_{T i}=\lambda_{T_{i N_{x}}}=18.0 \AA$ for Ti $2 \mathrm{p}$ electrons in Ti excited with Al $\mathrm{K}_{\alpha}$ -rays. $^{28}$ Thus, $d_{\text {TiN }}$ varies from $29 \AA$ with $p_{N 2}=92 \mathrm{mPa}$ to $34 \AA$ with $p_{N 2}=200 \mathrm{mPa}$, which is in very good agreement to the calculated compound thickness of $32 \pm 2 \AA$. Hence, over the entire $p_{N 2}$ range, TRIDYN simulations produce $\mathrm{N}$ implantation profiles that fit changes observed in the XPS spectra, which gives a consistent picture of target chemistry.

In conclusion, ex situ XPS analyses of native Ti target surfaces after sputtering in $\mathrm{Ar} / \mathrm{N}_{2}$ gas mixtures are demonstrated. In situ capped targets, with a 50- $\AA$-thick Al layers to prevent oxidation upon air exposure during transfer to the XPS instrument, allow precise assessment of target chemistry, while avoiding destructive effects of $\mathrm{Ar}^{+}$ion etch. Contrary to previous reports, where the formation of stoichiometric TiN on targets sputtered in $\mathrm{Ar} / \mathrm{N}_{2}$ gas mixtures was taken for granted, we demonstrate here, based on high-resolution core-level spectra supported by TRIDYN simulations, that $\operatorname{TiN}_{x}$ forms with $x$ ranging from 0.27 to 1.18 depending on $p_{N 2}$. At high $p_{N 2}$ values, $\geq 92 \mathrm{mPa}$, restrictive modelling allows to estimate the compound layer thickness, which is in a very good agreement to TRIDYN-simulated $\mathrm{N}$ implantation profiles. These results demonstrate the versatility of the capping technique, which allows to study the surface chemistry of regular process targets along with corresponding films. The method is inexpensive, straightforward, fast and therefore elegant, as opposed to complex, time demanding and very expensive solutions that employ in situ XPS.

The authors gratefully acknowledge the financial support of the German Research Foundation (DFG) within SFB-TR 87, the Swedish Government Strategic Research Area in Materials Science on Functional Materials at Linköping University (Faculty Grant SFO Mat LiU 2009 00971), the Åforsk Foundation Grant 16-359, and Carl Tryggers Stiftelse contracts CTS 15:219 and CTS 14:431. 


\section{Figure captions}

Fig. $1 \mathrm{Ti} 2 \mathrm{p}$ spectra acquired from Al-capped Ti target sputtered in $\mathrm{Ar} / \mathrm{N}_{2}$ mixture as a function of nitrogen partial pressure. The satellite peaks are marked with "S".

Fig. 2 XPS peak models of the Ti 2p spectra obtained from (a) metallic Ti, (b) native TiN film, and (c) Ti target surface sputtered at $92 \mathrm{mPa}$ nitrogen partial pressure. In the spirit of the Ockham's rule, the number of new component peaks is kept to the minimum yielding satisfactory fit.

Fig. 3 Nitrogen concentration profiles simulated by TRIDYN for $340 \mathrm{eV} \mathrm{Ar}^{+}$and $170 \mathrm{eV} \mathrm{N}{ }^{+}$ ions incident on the Ti target, as a function of $p_{\mathrm{N} 2}$. 


\section{References}

${ }^{1}$ O. Knotek, M. Böhmer, T. Leyendecker, J. Vac. Sci. Technol. A 4 (1986) 2695

${ }^{2}$ T. Leyendecker, O. Lemmer, S. Esser, J. Ebberink, Surf. Coat. Technol. 48 (1991) 175

${ }^{3}$ J.M. Molarius, A.S. Korhonen, E. Harju, R. Lappalainen, Surf. Coat. Technol. 33 (1987) 117

${ }^{4}$ V.R. Parameswaran, J.-P. Immarigeon, D. Nagy, Surf. Coat. Technol. 52 (1992) 251

${ }^{5}$ I. Petrov, E. Mojab, F. Adibi, J.E. Greene, L. Hultman, J.-E. Sundgren, J. Vac. Sci. Technol. A 11 (1993) 11

${ }^{6}$ J.S. Chun, P. Desjardins, C. Lavoie, C.-S. Shin, C. Cabral Jr., I. Petrov, J.E. Greene, J. Appl. Phys. 89 (2001) 7841

${ }^{7}$ S. Mráz and J.M. Schneider, J. Appl. Phys. 100 (2006) 023503

${ }^{8}$ S. Mráz and J.M. Schneider, Appl. Phys. Lett. 89 (2006) 051502

${ }^{9}$ D. Depla and R. De Gryse, Surf. Coat. Technol. 183, 184 (2004); 183, 190 (2004); 183, 196 (2004).

${ }^{10}$ S. Berg, H.-O. Blom, T. Larsson, and C. Nender, J. Vac. Sci. Technol. A 5, 202 (1987)

${ }^{11}$ T. Larsson, H.-O. Blom, C. Nender, and S. Berg, J. Vac. Sci. Technol. A 6, 1832 (1988).

9E. Kusano, J.

${ }^{12}$ J.-E. Sundgren, B.-O. Johansson, and S.-E. Karlsson, Surf. Sci. 128 (1983) 265

${ }^{13}$ D. Güttler, B. Abendroth, R. Grötzschel, W. Möller, and D. Depla, Appl. Phys. Lett. 85 (2004) 6134

${ }^{14}$ Y. Abe, T. Takisawa, M. Kawamura, and K. Sasaki, J. J. Appl. Phys. 46 (2007) 6778

${ }^{15}$ M. Audronis, G. Abrasonis, F. Munnik, R. Heller, P. Chapon, and V Bellido-Gonzalez, J. Phys. D: Appl. Phys. 45 (2012) 375203

${ }^{16}$ L. Combadiere, J. Machet, Surf. Coat. Technol. 82 (1996) 145

${ }^{17}$ D. Depla, J. Haemers. and R De Gryse, Plasma Sources Sci. Technol. 11 (2002) 91

${ }^{18}$ I. Takano, S. Isobe, T.A. Sasaki, Y. Baba, Appl. Surf. Sci. 37 (1989) 25

${ }^{19}$ J.A. Garcia, A. Guette, A. Medrano, C. Labrugere, M. Rico, M. Lahaye, R. Sanchez, A. Martinez, R.J.

Rodriguez, Vacuum 64 (2002) 343

${ }^{20}$ N. Heide, B. Siemensmeyer, J. W. Schultze, Surf. Interf. Anal. 19 (1992) 423

${ }^{21}$ S. Badrinarayanan, S. Sinha, A.B. Mandale, J. Electron Spectrosc. Relat. Phenom. 49 (1989) 303

${ }^{22}$ Ch. Kunze, D. Music, M. to Baben, J. M. Schneider, G. Grundmeier, Appl. Surf. Sci. 290 (2014) 504

${ }^{23}$ For more detailed treatment see, e.g. T. Wagner, J.Y. Wang, and S. Hofmann "Sputter Depth Profiling in AES and XPS" in "Surface Analysis by Auger and X-ray Photoelectron Spectroscopy" Ed. D. Briggs and J.T. Grant, IM Publications, Manchester, 2003, p.618 and references therein

${ }^{24}$ G. Greczynski, I. Petrov, J.E. Greene, and L. Hultman, J. Vac. Sci. Technol. A 33 (2015) 05E101-1

${ }^{25}$ G. Greczynski, D. Primetzhofer, J. Lu, and L. Hultman, Appl. Surf. Sci. 396 (2017) 347

${ }^{26} \mathrm{http}: / / \mathrm{www} . c e m e c o n . d e / c o a t i n g$ technology/coating units/hipims_sputter_coating system/index_eng.html, accessed on 2016-06-15

${ }^{27}$ G. Greczynski, S. Mráz, L. Hultman, J.M. Schneider, Appl. Phys. Lett. 108 (2016) 041603

${ }^{28}$ S. Tanuma, C. J. Powell and D. R. Penn, Surf. Interf. Anal. 43 (2010) 689

${ }^{29}$ Kratos Analytical Ltd.: library filename: "casaXPS_KratosAxis-F1s.lib"

${ }^{30}$ See for instance Chapter 1 in S. Hüfner "Photoelectron Spectroscopy: Principles and Applications", SpringerVerlag, Berlin, 2003.

${ }^{31}$ G. Greczynski and L. Hultman, ChemPhysChem (2017), DOI: 10.1002/cphc.201700126

${ }^{32}$ L. Porte, L. Roux, J. Hanus, Phys. Rev. B 28 (1983) 3214

${ }^{33}$ G. Greczynski and L. Hultman, Appl. Surf. Sci. 387 (2016) 294

${ }^{34}$ D. A. Shirley, Physical Review B 5 (1972) 4709

${ }^{35}$ See N. Fairley "XPS Lineshapes and Curve Fitting” in "Surface Analysis by Auger and X-ray Photoelectron Spectroscopy” Ed. D. Briggs and J.T. Grant, IM Publications, Manchester, 2003, p.397.

${ }^{36}$ L. Ramqvist, K. Hamrin, G. Johansson, A. Fahlman, C. Nordling, J. Phys. Chem. Solids 30 (1969) 1835

${ }^{37}$ B.J. Burrow, A.E. Morgan, and R.C. Ellwanger, J. Vac. Sci. Technol. A 4 (1986) 2463

${ }^{38}$ R.T. Haasch, T. -Y. Lee, D. Gall, J. E. Greene, and I. Petrov, Surface Science Spectra 7 (2000) 193

${ }^{39}$ N.C. Saha, H.G. Tompkins, J. Appl. Phys. 72 (1992) 3072

${ }^{40}$ L. R. Strydom and S. Hofmann, J. Electron Spectrosc. Relat. Phenom. 56 (1991) 85

${ }^{41}$ W. Möller and W. Eckstein, Nucl. Instrum. Methods Phys. Res. B 2, 814 (1984).

${ }^{42}$ W. Möller, W. Eckstein, and J. P. Biersack, Comput. Phys. Commun. 51, 355 (1988).

${ }^{43}$ I. Petrov, A. Myers, J. E. Greene, and J. R. Abelson, J. Vac. Sci. Technol. A, 12, 2846 (1994).

${ }^{44}$ G. Greczynski, J. Lu, M. Johansson, J. Jensen, I. Petrov, J.E. Greene, and L. Hultman, Surf. Coat. Technol. 206 (2012) 4202

${ }^{45}$ H. S. W. Massey and E. H. S. Burhop, Electronic and Ionic Impact Phenomena (Oxford University Press, London, 1956).

${ }^{46}$ A. Anders, Appl. Phys. Lett. 80 (2002) 1100 
${ }^{47}$ T. A. Carlson, Surf. Interf. Anal. 4 (1982) 125

${ }^{48}$ B.R. Strohmeier, Surf. Interf. Anal. 15 (1990) 51 


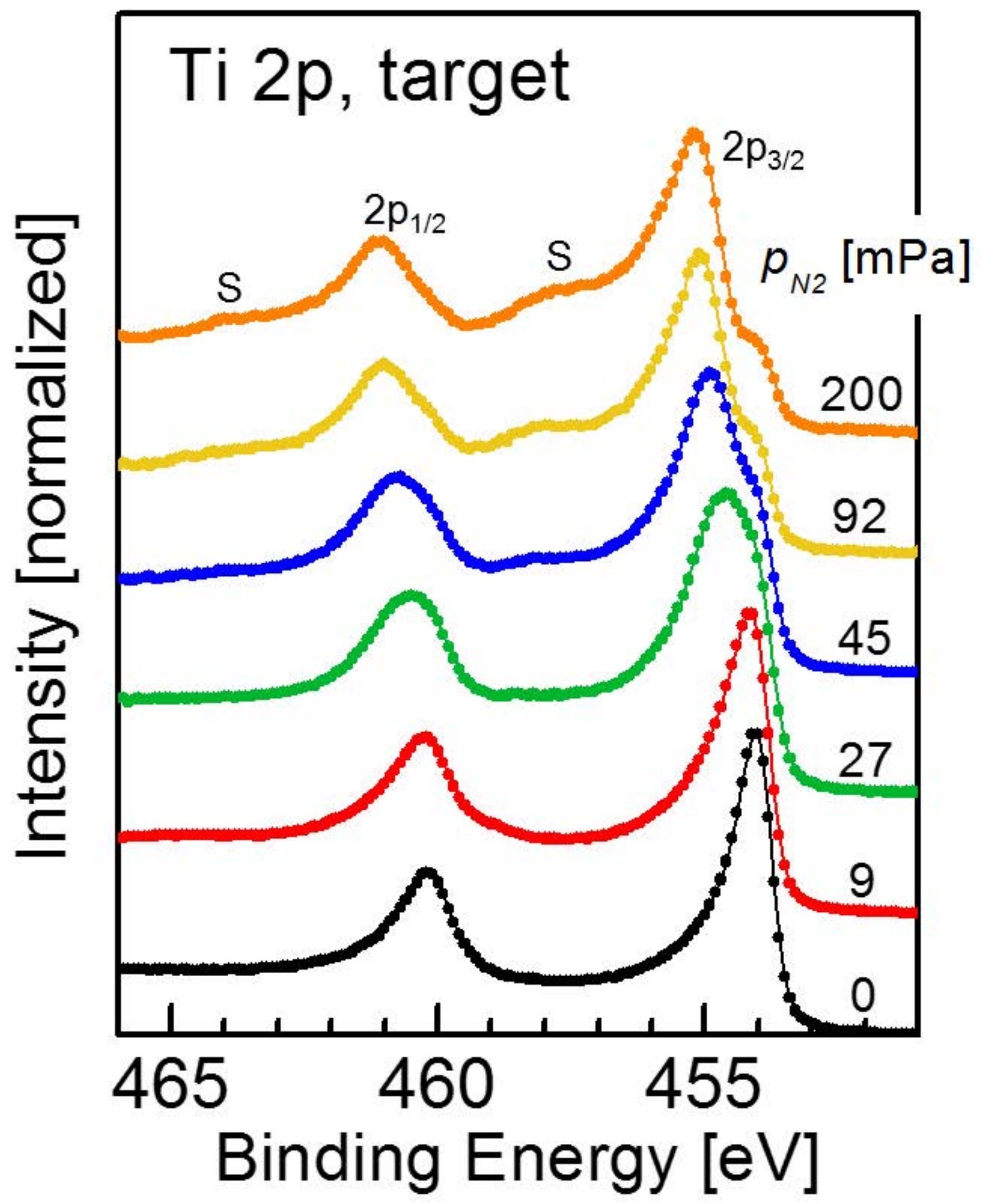

Fig. 1 

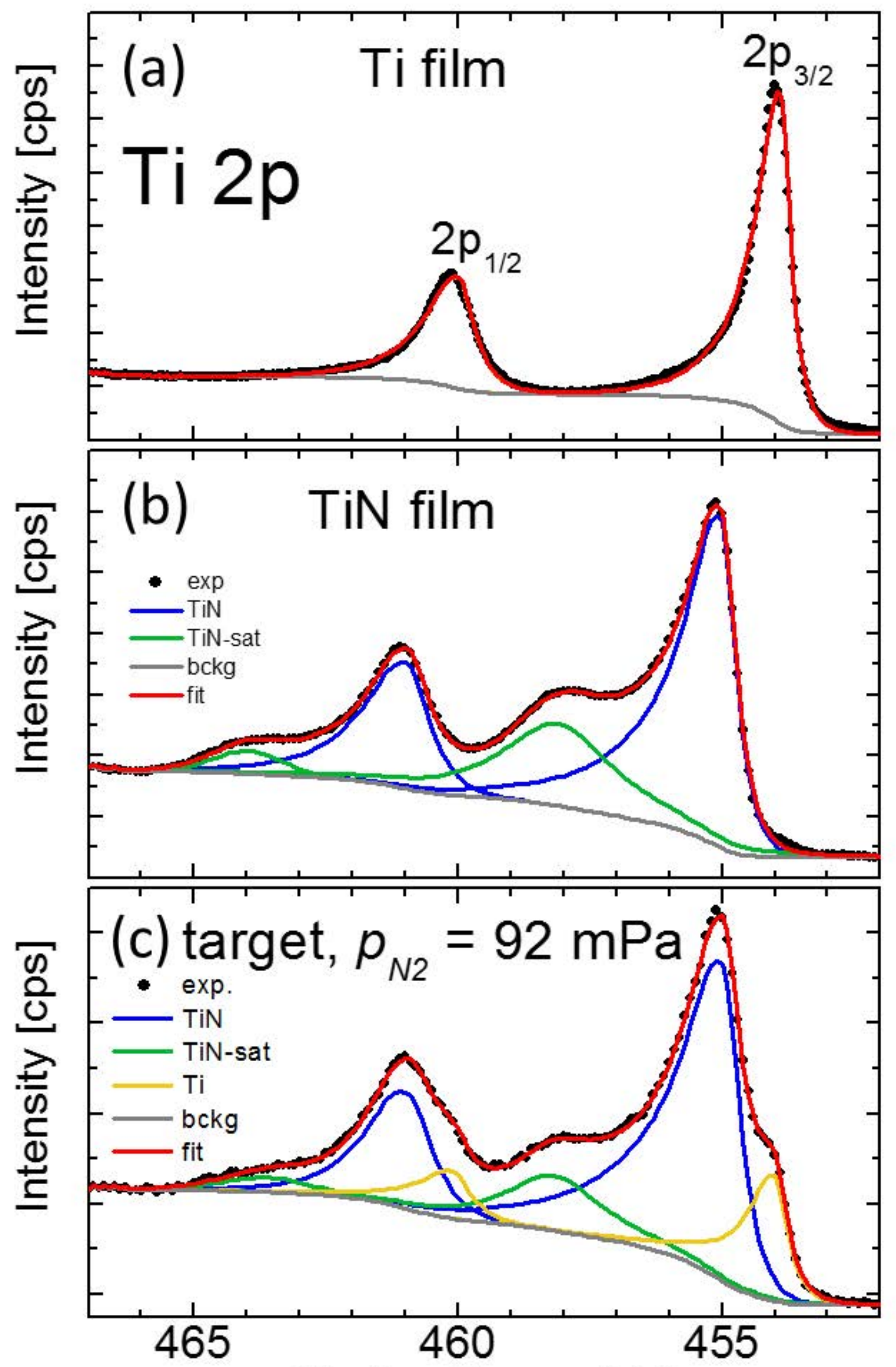

Fig. 2

Binding Energy [eV] 


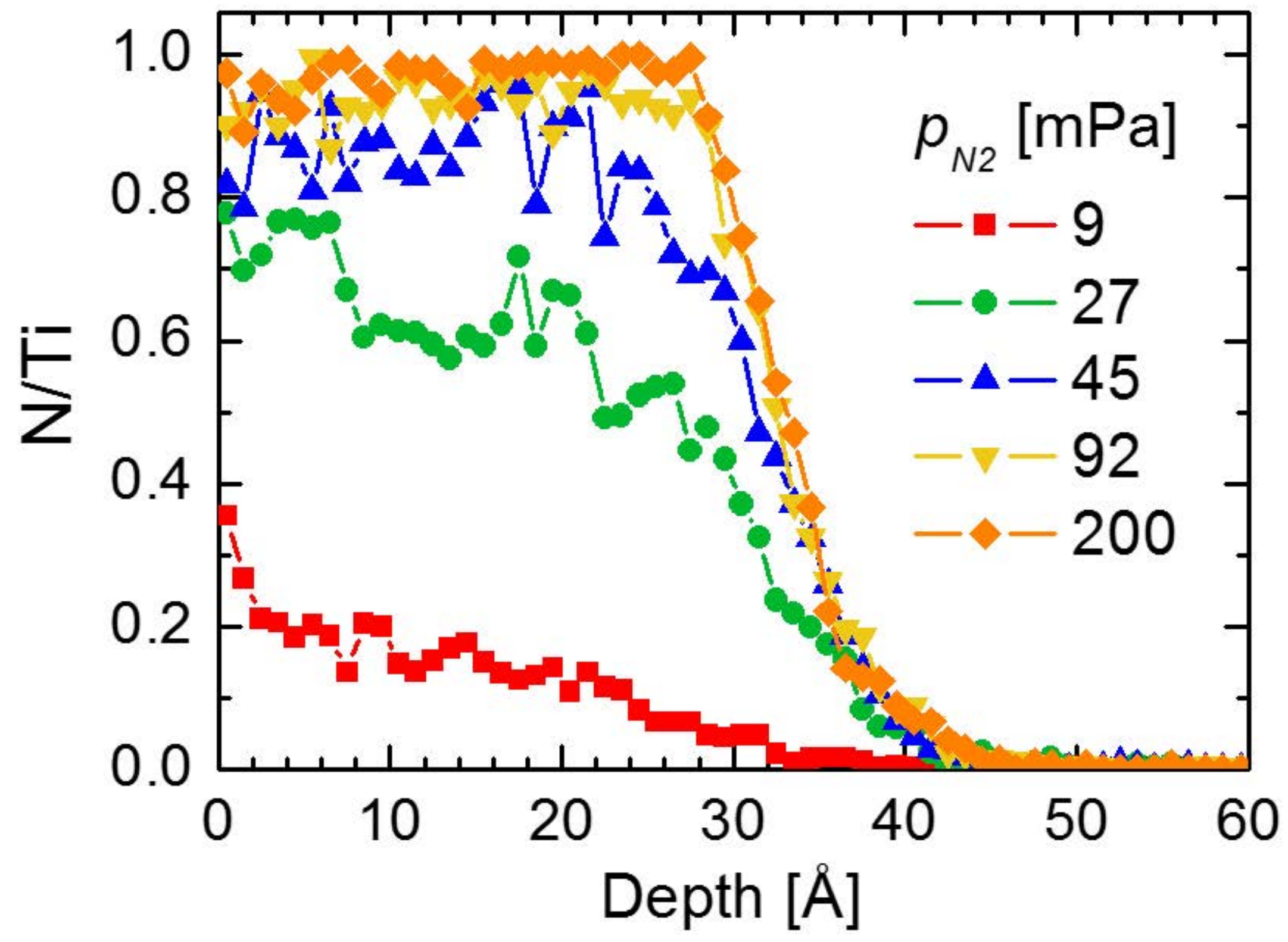

Fig. 3 